\title{
O plurilinguismo em Moçambique: debates e caminhos para uma educação linguística inovadora
}

\author{
Alexandre António Timbane \\ Universidade Federal de Goiás (Brasil-Moçambique) \\ José Gil Vicente \\ Universidade Salgado de Oliveira (Brasil-Moçambique)
}

\section{Introdução}

No mundo em que vivemos, as línguas desempenham um papel importante nas relações entre os humanos e com as tecnologias. A preocupação com as línguas não é recente, pois em muitos casos as línguas estão ligadas à identidade do grupo cultural em que os falantes estão inseridos. Existem a) línguas naturais: aquelas que surgiram e se formaram sem nenhuma intervenção intencional do ser humano, tais como xichangana, isizulo, cabo verdiano (em África), guarani, nheengatu, tukano (nas Américas), o japonês, gujarati e o mandarim (na Ásia), francês, italiano e espanhol (na Europa) e por aí em diante, e b) línguas artificiais: aquelas que são criadas/inventadas pelo homem com objetivo de atender objetivos especificamente econômicos, políticos e de lazer e não culturais. Pode-se citar exemplos das línguas interlíngua, rugresk, esperanto, glosa, valapuque, kulturkampf (Borba, 1967). A língua dothraki é artificial e é falada nas crônicas Gelo e Fogo de George Martiné; a língua sildavo criada para as histórias As aventuras de Timtim; a língua kindon que foi criada por Marc Okrand nos filmes Star Trek e A jornada nas estrelas; A língua na'vi que foi inventada como língua alienígena no filme Avatar criado por Paul Frommer. Esses exemplos de línguas artificiais são usadas em contextos restritos e apresentam propriedades que diferenciam de uma língua natural que é flexível, adaptável, com signos arbitrários, que tem dupla articulação, tem produtividade e é heterogênea (Malmberg, 1971; Benveniste, 2005; Lyons, 1987).

Observa-se que muitos grupos sociais apresentam relações mais próximas devido ao uso da língua comum. Nos povos africanos, a língua está ligada à etnia, ao grupo sociocultural que comunga o mesmo idioma. É com a língua que os indivíduos estabelecem relações comunicativas, compartilhando assim experiências e os 
modos de ser e de estar na sociedade. No âmbito da política (propriamente dita) e na política econômica surgem organizações do tipo Comunidade de Países de Língua Oficial Portuguesa (CPLP), Países Africanos de Língua Oficial Portuguesa (PALOP), Conselho Superior de Língua Francesa, Organização Internacional de Francofonia, Commonwealth, Hispanofonia entre várias outras que visam se agrupar para compartilhar e resolver problemas políticos e econômicos que enfrentam.

As línguas estão distribuídas de forma desigual no mundo, havendo continentes com mais e outros com menos línguas. Segundo Calvet (2012), é na Ásia onde se tem o maior número de línguas (33\%). Em África, fala-se 30\%; no pacífico 19\%; nas Américas 15\% e na Europa se fala 3\% (Calvet, 2007). Curiosamente, é no continente europeu onde se localizam as línguas oficiais no mundo, resultado da colonização declarada na Conferência de Berlin (1884-1885) pelas potências europeias. Nesse processo da colonização as línguas inglesa, francesa, portuguesa se espalharam pelas colônias criando, assim, variedades que hoje são utilizadas como línguas de prestígio nesses países. O inglês (em especial) é a língua oficial mais falada por africanos como segunda língua, tal como Rodrigues $(2005 ; 2011)$ aponta nas suas discussões.

É importante referir que há línguas descritas em África, mas também há muitas línguas que ainda não foram estudadas. As línguas não estudadas ou não divulgadas carregam um sentimento de inexistência uma vez que não possuem dicionário, nem gramáticas ou mesmo reconhecimento por parte da política linguística dos governos. Outra questão que merece ser apontada nesta introdução é a variabilidade do número de línguas em cada país, principalmente em países africanos. Isso se deve ao número exíguo de pesquisas sobre essas línguas, assim como à problemática dos debates sobre os limites entre língua, variedade, variante e dialeto. Acerca da diminuição de falantes de línguas africanas, atitude que coloca em perigo de extinção às várias línguas locais, Rodrigues (2005, p.162) aponta que, no continente africano,

o uso maciço de línguas europeias nos domínios oficiais atua em sentido oposto ao de uma suposta identificação comunitária e gera, em reação a ela, movimentos de resistência que visam à afirmação da diversidade cultural, à democratização do conhecimento e à implementação de políticas sociais mais justas e inclusivas.

Pouco se fala, mas os árabes foram pioneiros na navegação marítima e foram os primeiros a estabelecer contatos comerciais com os povos africanos, antes mesmo da chegada dos europeus. Foram os árabes que trouxeram pela primeira vez os panos, as missangas e os espelhos e outros objetos de troca pelo ouro e 
marfim com os líderes africanos. Nessa caminhada difundiu a religião muçulmana em quase todo continente com maior incidência na África do norte, ocidental e oriental.

Aproveitamos a ocasião para apontar que os contextos da colonização fizeram surgir pidgins e crioulos de base inglesa, portuguesa e hispânica principalmente na parte ocidental de África e nas suas respectivas ilhas (Tarallo; Alkmim, 1987). O plurilinguismo ou o multilinguismo é definido como a situação sociolinguística que se caracteriza pela convivência (harmoniosa ou conflituosa) de mais de três línguas no mesmo espaço político-administrativo. Esses fenômenos podem ocorrer em nível da comunidade (língua) ou em nível do indivíduo (fala). Portanto, numa comunidade monolíngue podemos encontrar cidadãos plurilíngues.

Aprender uma língua é ao mesmo tempo aprender uma cultura, pois língua e cultura estão intimamente interligadas. Assim, concorda-se com Lyons (1987), quando o autor afirma que a "cultura pode ser descrita como conhecimento adquirido socialmente: isto é, como o conhecimento que uma pessoa tem em virtude de ser membro de determinada sociedade" (Lyons, 1987, p.274). Nesse contexto, o multilinguismo tem sido confundido com o multiculturalismo. É que não existe uma cultura homogênea do mesmo modo que não existe uma língua homogênea. Tanto as línguas quanto as culturas estão em constante contato, variando, mudando e criando novas influências aos membros da comunidade.

Assim sendo, o plurilinguismo em África não é uma exceção, mas um fenômeno normal, pois quase todos os africanos falam, pelo menos, duas línguas. Algumas políticas e planejamentos políticos privilegiaram a oficialização de pelo menos uma língua africana. É o caso da Tanzânia que oficializou o swahili, tal como Rodrigues (2005) e Calvet (2007) demonstram com exemplos. Na África do Sul, por exemplo, temos o caso da oficialização de 11 línguas (Neville, 2013), na maioria, línguas do grupo bantu, atitude bem sucedida no que diz respeito à política e ao planejamento linguístico. Mais especificamente tratando dos objetivos dessa capítulo, Moçambique é um país africano de expressão portuguesa, tal como Angola, Guiné-Bissau, São Tomé e Príncipe e Cabo Verde. As características sociolinguísticas de Angola e de Moçambique são muito próximas, até porque historicamente não houve condições sociolinguísticas que fizessem surgir crioulos nem pidgins.

Segundo Calvet (2001), pode-se considerar três situações linguísticas em todo mundo: a) países que possuem uma única língua oficial (exemplo: Portugal, Moçambique); b) países oficialmente bilíngues (exemplo: Camarões que tem inglês e francês; Israel com hebreu e o árabe; Paraguai com espanhol e o guarani; Luxemburgo com alemão, francês e o luxoburguês; Bélgica com alemão, francês e 
holandês); c) países cujas línguas são oficialmente descentralizadas regionalmente (exemplo: Na África do sul, várias línguas do grupo bantu foram oficializadas; na Espanha, convive-se com basco, catalano e galego; na Suíça, convive-se com alemão, italiano, romeno) (Calvet, 2001).

Moçambique possui uma única língua oficial, a LP, instituída, investida e protegida pela Constituição da República (Moçambique, 2004). Entendamos uma língua como a parte social que é depositada virtualmente nos cérebros dos indivíduos pertencentes a uma comunidade linguística. $\mathrm{O}$ indivíduo sozinho não pode criar nem modificar a língua natural. A língua se opõe à fala que é individual e próprio do indivíduo. Por essa razão a língua deve ser estudada em si mesma e por si mesma (Saussure, 2006; Costa, 2009). É importante deixar claro desde já que a língua é um patrimônio extenso e ninguém a possui na sua totalidade, o que significa que cada falante retém uma parte do sistema dessa língua. Sendo assim, uma língua só se transforma através dos tempos porque os falantes introduzem inovações que só passam para o domínio da língua quando sai do individual para o coletivo.

O presente capítulo propõe-se, portanto, a estudar e avaliar as atitudes na concepção e representação das línguas no espaço onde elas ocorrem, mas também criar formas para ultrapassar - de uma vez para sempre - a visão colonial construída sobre a relação entre as línguas do colonizador e do colonizado. Seria importante e interessante desenhar estratégias de ação de médio e longo prazos, capazes de promover a justiça mundial no âmbito linguístico, pois a independência política já foi alcançada, mas falta a independência linguística, nos moldes como Ki-Zerbo (2006) nos propõe com sabedoria.

Nesse sentido, essa pesquisa aponta para o contexto sociolinguístico moçambicano, mas buscando experiências e políticas bem sucedidas de outros países. Para começar, levantamos uma questão de partida muito relevante, pois pretende-se saber se o plurilinguismo prejudica ou não o desenvolvimento econômico e educacional dos moçambicanos. Tentando responder provisoriamente a questão, pode-se afirmar que o plurilinguismo impede o aperfeiçoamento do português; a existência de várias línguas dificulta a escolha da língua oficial e prejudica o ensino do português; mas também as línguas bantu moçambicanas (LBm) não se afirmam e nem se difundem junto às populações devido à política linguística vigente.

Especificamente, a pesquisa irá: (a) descrever a situação linguística de Moçambique; (b) explicar como a política e o planejamento linguístico interferem no estado atual; (c) demonstrar como o plurilinguismo interfere no ensino médio e fundamental; (d) indicar caminhos possíveis para uma educação linguística inovadora. O capítulo inicia-se apresentando considerações importantes sobre o 
plurilinguismo em Moçambique, levantando um conjunto de elementos que contribuem para a emancipação linguística das línguas nativas. Mais adiante, aborda-se como as questões plurilíngues interferem na educação fundamental e média no espaço moçambicano. O capítulo termina discutindo e sugerindo caminhos linguísticos possíveis para uma política e planejamento linguística inovadores.

\section{Questões do plurilinguismo em Moçambique}

O território moçambicano é povoado predominantemente por populações do grupo bantu, distribuídas de forma desigual ao longo do vasto país. Segundo o INE (2007), o país conta com mais de vinte línguas do grupo, embora esse número seja discutido no seio de linguistas moçambicanos. Isso acontece por os limites entre línguas, dialeto, variedade e variante serem complexos naquele contexto, pois a língua não é apenas meio de comunicação, mas também objeto da cultura. A língua tem um valor cultural profundo que só pode ser determinada pelas tradições e culturas que habitam e que são praticadas por aquele povo. Cientificamente falando, a determinação de línguas só é possível graças aos estudos e pesquisas, o que ainda está sendo feito em universidades, com especial ênfase ao Departamento de línguas, Seção de Línguas Bantu da Universidade Eduardo Mondlane.

A pergunta mais frequente entre curiosos que pretendem saber algo sobre Moçambique é "quantas línguas se falam nesse país". Responder de forma categórica é tarefa complexa. Uma vez que a resposta esperada pelos curiosos não aparece de imediato, é interessante apresentarmos estudos publicados que resultam das pesquisas, debates e consensos entre pesquisadores moçambicanos, africanos e do mundo reunidos em Seminários temáticos sobre as LBm. Para Ngunga e Faquir (2011), estão padronizadas dezessete línguas todas do grupo bantu (Ngunga; Faquir, 2011). Esse número (17) resulta do trabalho realizado no III Seminário de Padronização ortográfica realizado em setembro de 2008. São elas: língua kimwani, shimakonde, ciyaawo, emakhuwa, echuwabu, cinyanja, cinyungwe, cisena, cibalke, cimanyika, cindau, ciwute, gitonga, citshwa, cicopi, xichangana e xirhonga (Ngunga; Faquir, 2011, p.v.).

Não é pelo fato de não terem sido padronizadas ortograficamente que as outras línguas não existam. Elas existem, são faladas por populações no cotidiano, mas para o seu reconhecimento pela política linguística é necessário que tenha dicionário, ortografia padronizada e gramática escrita. Alguém nos perguntaria: por que o número de falantes das LBm tende a decrescer nos últimos anos? Podemos responder afirmando que esse fenômeno resulta da política e do planejamento linguísticos que privilegiam o português em detrimento das restantes línguas locais. 
Uma vez que o português tem privilégio, consegue expandir-se com mais facilidade do que as LBm. E na África do Sul, por que ocorre situação tão diferente? É que as políticas linguísticas colocaram as línguas africanas no mesmo patamar que a língua do colonizador (o inglês) e essa política resultou na valorização das línguas africanas.

O quadro a seguir ilustra, de forma detalhada, a posição do português com relação às línguas moçambicanas, segundo Ngunga e Bavo (2011):

Quadro 1: Línguas, percentagens e províncias onde se fala

\begin{tabular}{|c|c|c|c|}
\hline $\mathrm{N}^{\mathrm{o}}$ & LÍNGUA & $(\%)$ & PROVÍNCIAS ONDE SE FALA \\
\hline 01 & Makhuwa & 26,1 & Cabo Delgado, Nampula, Niassa, Sofala e Zambézia \\
\hline 02 & Português & 10.8 & Todas \\
\hline 03 & Changana & 10.5 & Gaza, Maputo, Manica, Inhambane, Niassa \\
\hline 04 & Sena & 7.8 & Manica, Sofala, Tete, Zambézia \\
\hline 05 & Lomwe & 7.2 & Nampula, Niassa, Zambézia \\
\hline 06 & Nyanja & 5.8 & Niassa, Tete, Zambézia \\
\hline 07 & Chuwabu & 4.8 & Nampula, Sofala, Zambézia \\
\hline 08 & Ndau & 4.5 & Manica, Sofala \\
\hline 09 & Tswa & 4.4 & Gaza, Inhambane, Maputo, Sofala \\
\hline 10 & Nyumgwe & 2.9 & Manica e Tete \\
\hline 11 & Yaawo & 2.2 & Cabo Delgado e Niassa \\
\hline 12 & Copi & 1.9 & Gaza, Inhambane, Maputo, Manica \\
\hline 13 & Makonde & 1.7 & Cabo Delgado \\
\hline 14 & Tewe & 1.7 & Manica \\
\hline 15 & Rhonga & 1.5 & Gaza, Maputo, Manica, Inhambane \\
\hline 16 & Tonga & 1.5 & Gaza, Inhambane, Maputo, Manica \\
\hline 17 & Manyika & 0.9 & Manica \\
\hline 18 & Cibalke & 0.7 & Manica \\
\hline 19 & Mwani & 0.5 & Cabo Delgado \\
\hline 20 & Koti & 0.4 & Nampula \\
\hline 21 & Shona & 0.2 & Tete \\
\hline 22 & Swahili & 0.1 & Cabo Delgado \\
\hline 23 & Ling. sinais & 0.05 & Todas \\
\hline 24 & Outras ling. & 2.0 & Todas \\
\hline
\end{tabular}

Fonte: Adaptado de Ngunga e Bavo (2011, p.14-15)

O Quadro 1 mostra que os limites políticos são diferentes dos limites linguísticos. As línguas ultrapassam os espaços político-administrativos demarcados. Por essa razão, há línguas que são faladas em duas ou mais províncias (caso de sena) e línguas faladas internacionalmente (caso de swahili). A dinâmica dos cidadãos, 
os deslocamentos de uma região para outra devido à guerra e a concentração dos cidadãos nas cidades faz com que haja um contato constante e intenso entre línguas, o que resulta em um cenário multilíngue. Algumas dessas línguas são inteligíveis entre si (ronga, xitswa, changana) e outras não. São línguas de tradição oral e possuem pouca literatura escrita. Ao invés de aumentar o número de falantes, está se reduzindo devido ao prestígio do português.

Além disso, o gráfico 1 demonstra como o multilinguismo se torna uma situação "normal" entre os moçambicanos. Ele resulta de uma pesquisa de campo feito por Ponso (2014) sobre a situação sociolinguística de Moçambique:

Gráfico 1: O plurilinguismo em Moçambique

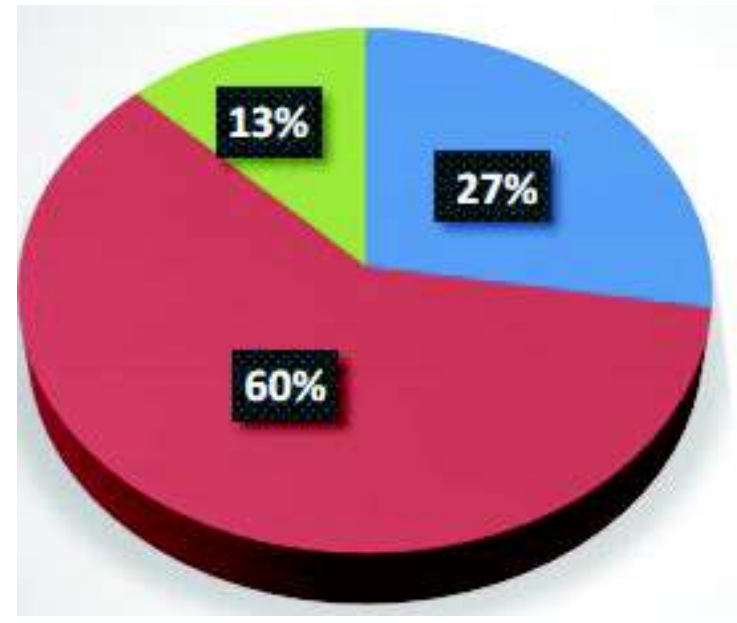

1 ou 2 línguas

de 3 a 5 línguas

6 a 8 línguas

Fonte: Ponso (2014, p.205)

Os dados de Ponso (2014), apresentados neste gráfico, mostram que o monolinguismo é anormal nesse contexto sociolinguístico, principalmente nas zonas rurais. Não percamos de vista que os povos bantu são de tradição oral e as regras de ser e de estar, bem como os hábitos culturais são transmitidos por meio dessas línguas. É importante deixar claro que o plurilinguismo não é problema para os povos africanos, em especial em Moçambique, mas uma solução num espaço multiétnico complexo. É uma forma de interação e junção de culturas. Os políticos encarregados por dirigir Moçambique no período pós-independência não pensaram desta forma. Para eles, a diversidade linguística e multiétnica era/é um grande problema, como se fosse possível encontrar um povo homogêneo em toda África bantu. Essa é a razão pela qual Moçambique, Angola, Guiné-Bissau, Cabo Verde e São Tomé e Príncipe oficializaram apenas o português deixando as línguas africanas faladas pela maioria da população. Isso prevalece até hoje e ainda há discursos que tendem a eliminar as etnias e as línguas faladas pelos diversos povos africanos. Uma das questões interessantes num espaço plurilíngue como o 
de Moçambique é que muitas línguas são inteligíveis e, em muitos momentos, os limites entre língua, variedade, variante e dialeto são pouco nítidas.

Tal como aconteceu com a maioria de países africanos, Moçambique oficializou a língua do colonizador num momento em que havia apenas $5 \%$ da população que falava português como língua materna. Timbane, Quebi e Abdula (2014) afirmam que África e, em particular os Países Africanos de Língua Oficial Portuguesa, tiveram a oportunidade de alcançar a independência linguística, mas não o fizeram por vontade própria. Observa-se, hoje, um crescimento da língua oficial e um decréscimo das LBm, o que não é saudável para a cultura e para as tradições.

Em muitos contextos, o português constitui um fator de exclusão social, cultural, econômico. Pensando nos problemas e constrangimentos que o português origina na vida social, cultural, educacional, Moçambique instituiu (em regime experimental) o ensino bilíngue português/línguas nativas nas classes (nos anos) iniciais. Em termos simbólicos, as línguas nativas passaram a ter mais sentido de valorização do que antes. Esse fato mostra que a educação constitui um elemento importante para a promoção social, cultural e, particularmente, linguística. No caso linguístico, a instituição do uso dessas línguas no ensino constitui um passo importante para a promoção das culturas veiculadas através dessas línguas.

Contudo, a concretização de um projeto de ensino bilíngue mais justo e válido no país passa, necessariamente, pela emancipação das línguas nativas. Um dos elementos para esse empreendimento é a sua descrição e, principalmente, a instituição de sua escrita. Isso significa que a escrita seria um elemento importante de preservação da cultura e do saber ligado a essas línguas. É verdade que os esforços para a valorização das LBm não faltam. Pode-se citar exemplos de Ngunga (2014), Ngunga et al. (2010), Nhampoca (2015), Timbane e Nhampoca (2016) entre muitos outros. Alguns estudiosos, organizações sociais e religiosas têm-se esforçado na descrição e no fornecimento de propostas de padronização das LBm. Porém, conforme avançado anteriormente, algumas delas carecem ainda de um benefício desse meio tecnológico tão importante para a promoção social e para a partilha do conhecimento.

\section{Elementos de emancipação linguística das línguas nativas e políticas}

Calvet (2001) sustenta que o plurilinguismo é um fator para conflitos, em função de seu viés de dominação, principalmente em povos cuja população é muito pequena. É de reconhecer, no entanto, os maiores obstáculos dessa ambiciosa orientação. Por exemplo, caberia observar que todo o trabalho acadêmico como o da descrição das línguas e sua padronização da escrita dependeria da disponibilidade de recursos econômicos. Assim, considerando a exiguidade de recursos 
econômicos no continente africano, também, traduzida em pouca produção intelectual, essa ambiciosa orientação exige medidas complementares, como, por exemplo, a criação e/ou aumento de fundos para a formação e para a pesquisa. Desse modo, caberia principalmente aos estudiosos africanos, particularmente aos linguistas, aprofundarem ainda mais suas propostas teórico-metodológicas de descrição e padronização das línguas africanas, privilegiando a emancipação.

A questão da emancipação das línguas nativas se mostra relevante na acumulação do conhecimento em África. Isso não significa, porém, o autofechamento dos conhecimentos africanos. Antes, constitui uma linha de orientação para a necessidade de abertura às outras línguas, de flexibilidade às mudanças sociais, culturais, políticas, científicas/tecnológicas, econômicas que se operam no mundo, explorando os bens que as diferentes sociedades proporcionam. Trata-se de uma orientação capaz de permitir a concretização de um projeto mundial e socialmente mais justo e capaz de permitir não só a coexistência de diferentes línguas e culturas, mas, também, um melhor conhecimento e uma melhor apreciação dos elementos de cada língua e cultura, particularmente em África.

Através dessa orientação, é possível ainda estabelecer relações de trocas positivas e de enriquecimento mútuo entre os elementos dessas diversas línguas e culturas. Assim, essas relações significariam igualdade e um permanente diálogo entre línguas e culturas, em que cada uma se valoriza através de práticas sustentáveis e permeáveis a um melhor conhecimento de si e (re) conhecimento das outras.

Desse modo, a pluralidade das línguas e, por via disso, das culturas, mostra-se como uma riqueza para a acumulação do conhecimento global. Para isso, é preciso, na prática, privilegiar a educação e a emancipação dos modos de concepção e representação das línguas, particularmente as africanas. É preciso propiciar práticas de inclusão, por meio de políticas de educação e de emancipação selecionadas sob a intenção de favorecer a compreensão das diferentes línguas e culturas presentes na África (e no mundo em geral). Isso significa uma rotura nas concepções e nas representações espaciais ou temporais de uso que se fazem do espaço e do tempo.

De forma concreta, isso significa novas concepções e representações das espacialidades e das temporalidades atuais, que se caracterizam por um capitalismo avançado, funcionando como a causa da globalização de línguas e culturas, e do apagamento de outras. Enfim, neste pensamento, é possível propor quatro linhas de orientação para a emancipação das línguas em África: a) reconhecer a importância do multilinguismo no continente; b) procurar potencializar a formação humana e as bases teórico-metodológicas na pesquisa, descrição e padronização 
das línguas africanas; c) vencer as concepções e representações sociais, políticas nocivas à emancipação das línguas africanas; d) valorizar as dinâmicas de promoção educativa em modelos bilíngues.

As questões de política e do planejamento linguístico são complexas e exigem muitas vezes a vontade e coragem política. Queiramos ou não, muitas realizações científicas só são possíveis graças à influência política disponível. Não adiantam as evidências científicas do pesquisador sobre um determinado assunto de interesse público, é necessário que haja interferência política para que isso se concretize, infelizmente. Nesse contexto, Calvet (2007) define política linguística como as decisões tomadas em nível político com relação ao uso e ao estatuto de uma ou varias línguas. Por outro lado, o planejamento seria a implementação prática das decisões políticas através da aplicação prática, sejam no ensino, no uso em instituições públicas etc. (Calvet, 2007). Para Cooper (Apud Severo, 2013, p.451), a política linguística "tem tradicionalmente se voltado para uma prática de caráter estatal-legislativo, debruçando-se, por exemplo, sobre a oficialização de línguas, a escolha de alfabeto para a representação gráfica de uma língua, a hierarquização formal das línguas (línguas de trabalho, oficiais, nacionais, por exemplo), entre outros." Por sua vez o planejamento linguístico "tem focado a implementação das decisões sobre a língua através de estratégias (políticas), como as políticas educacionais, com vistas a influenciar o comportamento dos sujeitos em relação à aquisição e uso dos códigos linguísticos" (Severo, 2016, p.451-452).

Antes da tomada de qualquer decisão, há um conjunto de questionamentos que se deve fazer para que a política decida. Calvet (2007) levanta sete dados importantes que passamos a citar: a) levantamento do número de línguas e de falantes; b) levantamento de línguas citadas pela constituição; c) observar a funcionalidade dessa(s) línguas(s), se são veiculares, transnacionais, do uso religioso ou outras; d) verificar a taxa de transmissão de geração para outra, e isso está ligado às taxas de natalidade; e) dados simbólicos, tais como sentimento linguístico, estratégias de comunicação e prestígio; f) dados conflituais (relações entre línguas).

Da lista de Calvet (2007), consideramos interessante a necessidade de publicar dicionário, estabelecer acordo ortográfico (ou padronização), gramática escrita e literatura. Se fosse por força de vontade dos pesquisadores das LBm, as línguas do grupo bantu faladas em Moçambique já teriam sido oficializadas nos locais onde elas ocorrem, já poderiam ser ensinadas nas escolas e já poderiam ter um estatuto privilegiado. $\mathrm{Na}$ entrevista com o professor e linguista moçambicano Bento Sitoe (Timbane; Nhanpoca, 2016), verificou-se claramente que a vontade dos pesquisadores moçambicanos está abaixo da vontade da política, pois projetos que visam estimular o desenvolvimento das LBm podem ser reprovados na Assembleia da República. 
Outros problemas que incomodam o planejamento linguístico são as chamadas TIC's (tecnologias de informação e comunicação). Por exemplo, Savero (2013) levanta problemas da experiência brasileira no município de São Gabriel da Cachoeira (estado do Amazonas) que oficializou línguas indígenas (tukano, baniwa e nheengatu), mas os seus cidadãos não conseguem registrar seus filhos com o nome indígena, porque não há nos computadores um teclado que represente graficamente os nomes indígenas. Observa-se que a grafia para um som tuiuca, aspirado entre $\mathbf{u}$ e $\mathbf{i}$ e representado como um $\mathbf{u}$ cortado, característico do nheengatu, não se consegue colocar nos teclados disponíveis. O importante para aquele povo indígena do Amazonas é a conquista que o Município de São Gabriel da Cachoeira conseguiu, ao colocar as línguas locais em patamar de igualdade com as línguas indígenas, atitude que trouxe prestígio e autoestima. Vejamos a seguir a posição política de Moçambique com relação às línguas locais.

\section{A educação fundamental e média VS as línguas no espaço moçambicano}

O sistema educativo público moçambicano se divide em fundamental, médio e superior. Existe o que se designa por ensino geral (quando a formação não especializa o estudante para uma determinada profissão) e ensino profissional (quando o estudante é direcionado e orientado para uma determinada profissão). Em todo percurso de formação escolar, a LP sempre acompanha os educandos, pelo fato de ser a língua oficial de Moçambique. Para Namone e Timbane (2017), "o processo de transformação da norma-padrão europeia em português de Moçambique, uma variedade que na base da LP adapta, integra na língua seus valores culturais, sua identidade, seus símbolos, seus objetos materiais de tal forma que seja sentida como pertence dos moçambicanos" (Namone e Timbane, 2017, p.47).

No contexto educacional moçambicano, há espaço para a aprendizagem das duas principais línguas internacionais, o francês e o inglês. O objetivo de aprendizagem de línguas estrangeiras modernas é o de preparar o estudante para que possa usufruir da bibliografia escrita naquelas línguas bem como da integração regional e internacional. Na África Austral, a maioria dos países é de expressão anglófona. Entendemos que as línguas que circulam no espaço escolar interessam à política linguística do país, exceto as LBm. Os materiais usados no ensino foram produzidos por docentes moçambicanos e refletem, em algum modo, as realidades sociolinguísticas e culturais dos moçambicanos. A formação de docentes de línguas estrangeiras modernas é garantida pelas universidades públicas e privadas.

Com relação às $\mathrm{LBm}$, é importante referir a importância de pesquisadores e docentes da Universidade Eduardo Mondlane que contribuem fortemente para a 
criação de materiais e para a divulgação de estudos sobre essas línguas. Não é uma tarefa fácil, pois a política e o planejamento linguístico pouco fazem para fortalecer e dar melhor espaço a essas línguas.

Falando sobre e educação bilíngue em LBm, Nhampoca (2015) aponta que 19 línguas bantu são ensinadas em nível de graduação, concretamente na Universidade Eduardo Mondlane (Nhampoca, 2015, p.85). A autora enumera cibalke, cicopi, cindau, cimanyika, cinyanja, cinyungwe, cisena, citshwa, ciute, ciyaawo, echuwado, ekoti, elomwe, emakhuwa, gitonga, kimwani, shimakonde, xichangana e xirhonga. Entendemos que a formação de recursos humanos para lidar com as LBm em sala de aula é relevante e que deve ser incentivada com a adoção de políticas públicas que estimulem estudos, pesquisas, elaboração de materiais bem como a criação literária. Hierarquizando o multilinguismo no contexto de Moçambique, temos a seguinte ilustração representada pela figura 1:

Figura 1: Características do multilinguismo no contexto moçambicano

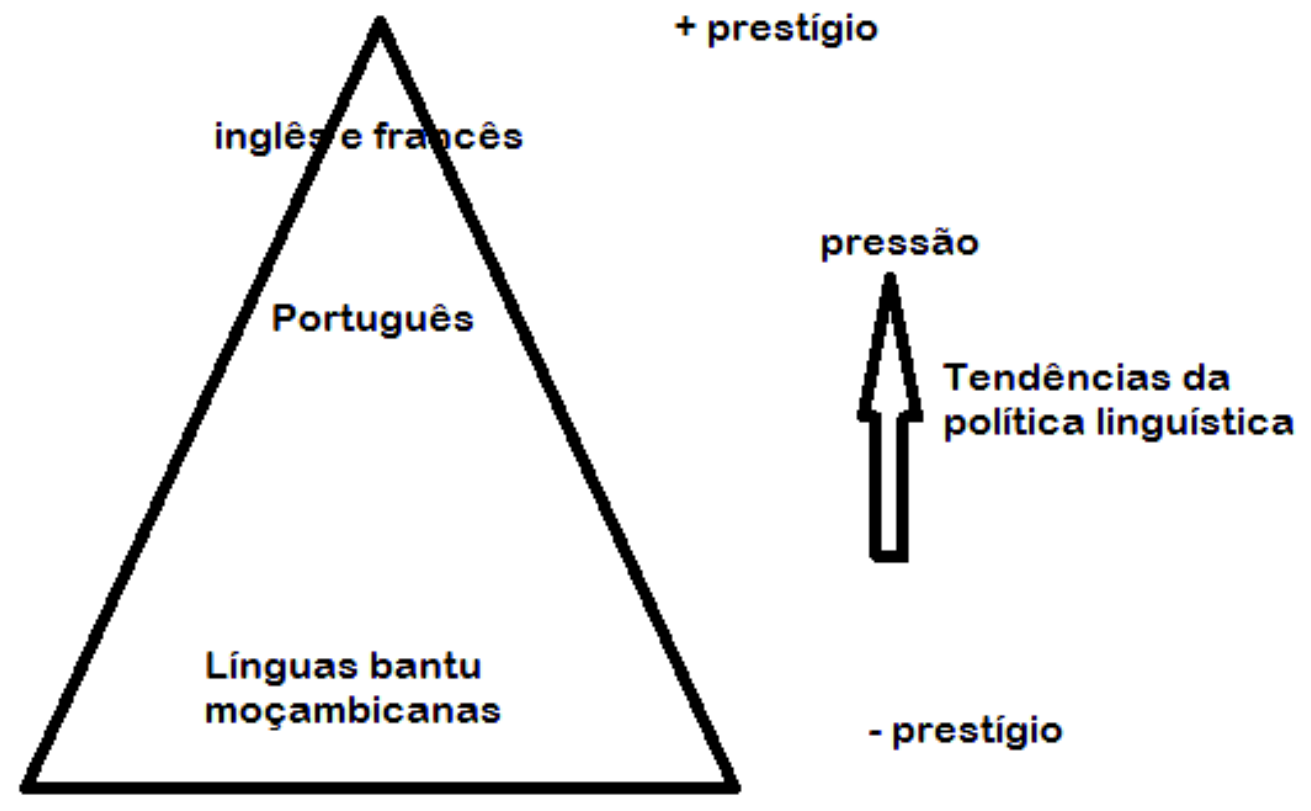

Fonte: Elaboração própria

Em termos numéricos ou percentuais, percebe-se que cidadãos que estão na base do triângulo são usuários/falantes de pelos menos uma LBm como língua materna. O crescimento do português é preocupante nas zonas urbanas e menos impactante nas zonas rurais de Moçambique, enquanto que o conhecimento das línguas estrangeiras modernas é interessante nas relações internacionais. $\mathrm{Na}$ base do triângulo da fig.1, localiza-se uma população sociolinguisticamnete bem estruturada, analfabeta ou pouco alfabetizada, de classe social baixa ou média, localizada estrategicamnete nas áreas urbanas. 
Nessa representação, observa-se que há uma pressão forte de baixo para cima com vista a alterar o cenário, puxando as camadas analfabetas para utilizarem a língua de prestígio. A tendência política é a de fazer com que o triângulo se inverta, fazendo com que todos os moçambicanos falem português. Esta política já foi bem sucedida no Brasil com a política de Marquês de Pombal (período 1654-1808). No período colonial, todos os índios e africanos que recusavam falar português eram mortos, assassinados e excluídos - atitude que acelerou a inversão que prevemos para o contexto de Moçambique.

A pressão não ocorre apenas com a língua oficial, a LP, mas também ocorre com as línguas estrangeiras modernas, como é o caso do francês, do espanhol e do inglês. Em Moçambique, muitos pais matriculam seus filhos em creches e escolas bilingues (português-inglês) na expectativa de que estas crianças possam ter mais oportunidades de emprego no futuro. Entendemos esta atitude como uma mera ilusão, pois se assim fosse condição de obtenção de emprego nenhum cidadão anglófono estaria no desemprego. Trazendo uma breve comparação com o contexto do Brasil, é perceptível a ameaça que as 170 línguas indígenas (Rodrigues, 2010) estão correndo nos últimos anos. As Diretrizes Curriculares Nacionais da Educação Escolar Indígena (Brasil, 1999a, b) mostram claramente como a política educacional dá pouca ênfase às línguas locais valorizando sempre a língua oficial, a LP.

O preconceito linguístico é muito frequente nas nossas sociedades. No caso de Moçambique, Nhampoca (2015) levanta três problemas que impedem o crescimento da educação bilingue, nomeadamente, 1) a incredibilidade (os próprios moçambicanos não acreditam na capacidade das suas línguas, mas também a pouca inteligibilidade entre línguas, atitude que pode limitar o contato com cidadãos falantes de outras línguas); 2) a incapacidade (falta de recusros financeiros para elaboração de materiais didáticos); e 3) o extremismo (abandono da língua oficial em detrimento das línguas bantu).

Na pesquisa de Ponso (2014, p.214), questionou-se se os inquiridos tinham sofrido algum tipo de repressão ao ter falado uma LBm na escola ou em lugar público. A resposta confirma as nossas colocações, pois $82 \%$ afirmaram ter sofrido. Os estudos de Ponso (2014) apontam que os inquiridos gostariam de aprender as línguas bantu (97\%), acham importante aprender uma língua bantu (92\%), mas infelizmente não há políticas públicas que incentivem esse desejo dos moçambicanos.

O plurilinguismo na lusofonia acelera a variação do português. Observando para Guiné-Bissau, por exemplo, Couto e Embalô (2010) citam as palavras candonga (pequeno veículo de transporte popular interurbano), bajuba (moça, 
rapariga), bolanha (arrozal), chebéu (dendê), tabanka (agrupamento típico de casas africanas) que resultam do contato entre o português, o crioulo e as diversas línguas bantu, tais como balanta, fula, mandinga, manjaco, papel, biafada, mancanha, delupe, nalu (Namone; Timbane, 2017). O Artigo 23ㄹ UNESCO (1996, s.p) defende que

1. O ensino deve contribuir para fomentar a capacidade de auto-expressão linguística e cultural da comunidade linguística do território onde é ministrado. 2. O ensino deve contribuir para a manutenção e o desenvolvimento da língua falada pela comunidade linguística do território onde é ministrado. 3. O ensino deve estar sempre ao serviço da diversidade linguística e cultural, e das relações harmoniosas entre as diferentes comunidades linguísticas do mundo inteiro. 4. No quadro dos princípios anteriores, todos têm direito a aprender qualquer língua.

Estas constatações da UNESCO através da Declaração de Direitos Linguísticos são pouco observadas pelos governos africanos em especial em Moçambique, visto que se adota políticas que desprotegem as línguas locais, causando reprovações em massa em todos os níveis de ensino. Em caso de aprovação, cultivam-se analfabetos funcionais, pois ao fim de cada grau as dificuldades continuam e ficam mais expostos devido à dificuldade de lidar com a língua em situações concretas de trabalho.

\section{Descaminhos linguísticos em Moçambique globalizado: análises e dados}

A língua é, sem dúvidas, um complexo instrumento de comunicação entre os humanos. Ela está impregnada na cultura e todos os significados só são compreendidos dentro da cultura. Eliminar a línguas locais é eliminar traços culturais e históricos de um povo ou de uma comunidade. Existem realidades sociolinguísticas que só são interpretadas dentro da cultura. A língua é uma das manifestações culturais que fundamentam a identidade de um povo. As diferentes identidades linguísticas são estruturadas logo no início da vida, no momento em que começa o processo de interação com os familiares, vai prosseguindo com o decorrer das interações nos diferentes meios que circundam o indivíduo, existindo, assim, uma permanente mudança de bases identitárias.

Existem caminhos possíveis que possam apoiar e preservar o multilinguismo no contexto de Moçambique. Nas três situações propostas por Calvet (2001), Moçambique caberia na situação 3 , em que teríamos várias línguas oficiais em diversas regiões do país. Alguns estudos revelam caminhos interessantes. Primeiro, é preciso deixar claro que Moçambique, no período pós-colonial (1975), viveu momentos de incertezas porque a educação do sistema colonial já não respondia plenamente aos anseios da sociedade. Por exemplo, o sistema colonial obrigava o 
ensino da História e da Geografia de Portugal apenas. Esta intenção foi substituída pelo ensino da História e Geografia de Moçambique. A gramática se baseava numa única obra: "Gramática portuguesa" de José Maria Relva. Esta obra foi substituída por manuais escolares que se adaptavam à realidade moçambicana.

Ao adotar apenas o português como a única língua oficial de Moçambique, os moçambicanos perderam a oportunidade de impulsionar o crescimento qualitativo e quantitativo das LBm. Concordamos com Nhampoca (2015) quando defende a ideia segundo a qual a educação bilíngue trouxe inclusão tanto para os falantes bem como o prestígio e valorização das LBm. A posição de Nhampoca vai ao encontro do que aparece na Carta dos Direitos Linguísticos da UNESCO, que no art. $29^{\circ}$ aponta que "Todos têm direito ao ensino na língua própria do território onde residem" e no art. 38 "Todas as línguas e todas as culturas das comunidades linguísticas devem receber um tratamento equitativo e não discriminatório nos conteúdos dos meios de comunicação do mundo inteiro".

O mundo globalizado em que vivemos exige o domínio de línguas estrangeiras. As oportunidades de um bom emprego, de um bom negócio internacional dependem da forma como os sujeitos dominam as línguas estrangeiras. Não é por acaso que cidadãos que dominam a língua inglesa, por exemplo, possuem mais possibilidades de emprego se compararmos com os que são monolíngues, mas há necessidade de combater o preconceito linguístico com relação às LBm. Com isso não pretendemos dizer que o conhecimento de uma língua estrangeira seja tudo na vida profissional. É importante o domimio de outras competências.

O plurilinguismo não é uma questãorelevante apenas para o contexto educacional de Moçambique. Ndombele (2017) reporta esse debate na sua pesquisa "Gestão de multilinguismo em Angola: reflexões sobre o ensino de línguas angolanas de origem bantu na província de Uinge". Além disso, Namone e Timbane (2017) discutem sobre as "Consequências do ensino da língua portuguesa no ensino fundamental na Guiné-Bissau 43 anos após a independência”. Por sua vez, Gonçalves e Hagemeijer (2015) dissertam sobre o tema: "O português num contexto multilíngue: o caso de São Tomé e Príncipe”. A lista de pesquisas recentes sobre o plurilinguismo poderia seguir mais adiante. Uma vez identificados os problemas nos PALOP, há necessidade de procurar caminhos ou pelo menos tentativas de resolver os problemas deixados pelo sistema colonial e também pelos governos pós-independência. A próxima seção (que apresentaremos adiante) não resolve os problemas do plurilinguismo na lusofonia africana, mas aponta alguns caminhos que podem ser trilhados rumo à melhoria da qualidade de ensino e à preservação e uso das línguas africanas como línguas verdadeiramente úteis para a vida das populações. 
Calvet (2007) apresenta-nos uma experiência da promoção de uma língua veicular, na Tanzânia que vale apena discutir aqui. Primeiro o autor explica que na Tanzânia há cerca de 130 línguas e as línguas estão divididas em três grupos:

$1^{\circ}$ há línguas primeiras da população, em grande maioria bantas, com minorias cuchíticas e nilóticas e algumas línguas asiáticas faladas dos migrantes; $2^{\circ}$ há uma língua veicular que se tornou nacional, mais ou menos bem falada, de acordo com idade das pessoas: suaíli; $3^{\circ}$ há uma língua legada pela época colonial: o inglês (Calvet, 2007, p.118).

Felizmente, a situação sociolinguística de Moçambique é mais favorável se compararmos pelo número de línguas e do multilinguismo. Desta forma,

\begin{abstract}
é neste contexto que a educação bilíngue surge da necessidade de se proporcionar às crianças a escolarização na sua língua materna e também em língua portuguesa (que, como língua oficial, funciona também como língua segunda), valorizando o conhecimento linguístico que o aprendente transporta consigo, traduzido em facilidade de comunicação, rápido acesso ao conhecimento científico e na integração consentânea na escola" (Chicumba, s.d., p.251).
\end{abstract}

É verdade que a África “contribuiu para seu próprio declínio, dado que alguns grupos sociais africanos ajudaram a explorar África" (Ki-Zerbo, 2006, p.132). Por que Ki-Zerbo chega a essa conclusão? É que os próprios africanos escolheram caminhos errados ao tomar apenas a língua do colonizador, deixando de lado as línguas africanas faladas pela maioria da população. No caso de Moçambique, em 1975, ano da independência, havia apenas 1,2\% da população que falava português como língua materna. Qual foi a razão da recusa das línguas da maioria? Justamente pela dependência e pela necessidade de receber apoios econômicos que em nada ajudavam ao resto da população. Esse é um descaminho que, de certa forma, ainda se paga a fatura dela. É interessante questionarmos: afinal que tipo de cidadão pretendemos formar? Um cidadão que perdeu a sua língua, seus traços culturais e sem identidade? Afinal, o que é uma língua e qual é o seu papel na cultura? Essas perguntas são provocativas, mas que nos conduzem a uma reflexão profunda sobre o que perdemos e o que se pode resgatar rumo a uma educação linguística mais humana e sem preconceito.

\title{
5. Caminhos para uma educação linguística inovadora em Moçambique
}

Não seria justo terminarmos os debates sem indicarmos possíveis caminhos para uma educação linguística inovadora sem preconceito, principalmente no espaço escolar. A nossa sociedade sempre coloca as línguas numa hierarquia que na prática não devia existir. Não existe uma língua inferior, feia, sem valor, assim como não existe uma língua sem gramática ou com estrutura simples e/ou pobre. 
Todas as línguas têm o seu valor social e cultural nos espaços onde são faladas e/ou escritas. É verdade que existem muitas línguas ágrafas no séc. XXI, mas a escrita é um complemento. A oralidade sempre tem tido um espaço privilegiados em quase todas as sociedades. Comparando a fala e a escrita, fica clara a ideia de que a oralidade ocupa um espaço mais avantajado.

Antes de avançarmos nesta parte seria interessante retomar as afirmações do Ki-Zerbo (2006) quando aponta que a educação deve ser considerada como o coração do desenvolvimento. Isso se justifica muito mais hoje, porquanto o principal investimento é o da inteligência, da matéria cinzenta. Segundo Ki-Zerbo, mais do que nunca, a educação e o desenvolvimento devem ser postos em equação, na condição de tratar-se de uma educação adaptada. É aqui que é necessário sair do mimetismo, da cópia pura e simples dos modelos vindos de fora. Tal como existe hoje, a educação é um processo de antidesenvolvimento (Ki-Zerbo, 2006).

A maioria das crianças africanas recebe hoje uma educação que destrói o seu futuro em todos os planos. Em muitos aspectos, seria possível dizer que temos interesse em diminuir o número de escolas, porque elas não estão adaptadas aos nossos países, nem cultural nem socialmente. O sistema está adaptado ao sucesso individual de uma minoria, que é bem-sucedida, não por causa do sistema, mas apesar dele. Sem contar que, qualquer que seja o sistema, os espíritos superiores terão sempre sucesso (Ki-Zerbo, 2006).

Analisando as reflexões de Ki-Zerbo, ficamos com a ideia clara sobre Moçambique e também no resto dos PALOP, pois pouco se faz em prol das línguas locais. Se "a educação deve ser considerada o coração do desenvolvimento" (Ki-Zerbo, 2006, p.150), então maiores investimentos poderiam ser colocadas em prol da educação. Não existiram ainda crianças que estudam debaixo das árvores, não existiria a obrigatoriedade de aprender apenas em português, as escolas estariam apetrechadas e o ensino seria de qualidade. Mas o que se verifica é o esquecimento do setor educativo apostando-se sempre em aprovações automáticas como forma de preparar futuros analfabetos funcionais. Entendamos analfabetos funcionais indivíduos (com 15 ou mais anos) que, embora saibam reconhecer letras e números, são incapazes de compreender textos simples, bem como realizar operações matemáticas mais elaboradas.

Nenhum estudo foi feito em Moçambique (provavelmente nos PALOP) sobre o analfabetismo funcional nem sequer as causas da sua existência. Entendemos que a língua oficial seja o principal fator, acrescido da formação do professor e das condições das escolas moçambicanas. Entendemos que existe uma relação entre o analfabetismo funcional e a formação do professor, porque um professor mal formado e sem motivação se preocupará em preencher estatísticas de aprova- 
dos sem prestar atenção na qualidade e na transmissão do saber científico. Uma educação inovadora valoriza as diferenças e aproveita esse potencial para trazer mais valia na formação de jovens, adolescentes e adultos. A existência de muitas línguas no país só exige apenas uma formação sólida e profunda dos professores de línguas.

Entendemos que o plurilinguismo reflete a riqueza cultural de uma nação. As diferenças são uma característica normal em todas as nações do mundo. Imaginemos se todos tivéssemos uma mesma cultura e uma mesma língua! Praticamente não haveria muito interesse. $\mathrm{O}$ mundo é feito de diferenças em tudo e em todos. Os estudos de Ntondo (2006) e Chicumba (s.d.) em Angola, os estudos de Ngunga et al. (2010) e Ngunga e Bavo (2011) em Moçambique entre outros revelam como a multiplicidade de línguas reflete a organização étnica do seu povo. Para Ndombele "cada língua africana de origem angolana normalmente está associada a um grupo étnico ao qual o indivíduo pertence ou à aldeia de onde seus pais são originários." (Ndombele, 2017, p.40).

A diversidade linguística é um patrimônio da humanidade que deve ser valorizado e protegido; o respeito por todas as línguas e culturas é fundamental no processo da construção e manutenção do diálogo da paz e no desenvolvimento do mundo; todo humano tem direito de aprender na sua própria língua; as línguas são apenas instrumentos de comunicação, mas também defensores da cultura e da identidade; a tradução, a interpretação na língua do sujeito é um direito. A Declaração Universal dos Direitos Linguísticos considera que o direito ao ensino da própria língua e da própria cultura; o direito a dispor de serviços culturais; o direito a uma presença equitativa da língua e da cultura do grupo nos meios de comunicação; o direito a serem atendidos na sua língua nos organismos oficiais e nas relações socioeconômicas (UNESCO, 1996, s.p.) são indicações fundamentais para que tenhamos uma sociedade mais democrática linguisticamente.

\section{Conclusões}

O plurilinguismo é uma realidade no contexto moçambicano. Tanto nas zonas urbanas quanto nas suburbanas e rurais as línguas se entrelaçam. A política da eliminação das etnias e da unidade nacional que tanto se discutiu e implementou no período pós-independência criou, cada vez mais, um Moçambique multilíngue e multicultural. O plurilinguismo não prejudica o desenvolvimento econômico e educacional dos moçambicanos, mas sim cria um espaço democrático mais sólido porque, afinal, não existem culturas nem povos homogêneos. A existência da diversidade em toda sociedade constitui uma riqueza cultural importante. No entanto, isso precisa ser valorizado com a oficialização e ensino das diversas LBm 
faladas pela maioria da população. Tal como os Direitos Linguísticos afirmam, aprender na sua língua materna tem mais vantagem porque:

a) Há valorização da língua do falante e da comunidade;

b) Há preservação do patrimônio cultural linguístico;

c) Evita-se a extinção das línguas nas gerações vindouras e

d) Reforça a autoestima e evita preconceito linguístico.

Nesta pesquisa de caráter bibliográfico, procuramos compreender a importância do plurilinguismo no desenvolvimento da educação linguística dos moçambicanos. Tentamos (a) descrever a situação linguística de Moçambique; (b) explicar como a política e o planejamento linguístico interferem no estado atual; (c) demonstrar como o plurilinguismo interfere no ensino médio e fundamental; (d) indicar caminhos possíveis para uma educação linguística inovadora. Entendemos que a oficialização das diversas LBm seria interessante no contexto atual de Moçambique por forma a que estas não desapareçam com o tempo.

Para finalizar, é importante dizer que a educação em Moçambique pode melhorar se houver vontade política, se cada professor contribuir dentro das possibilidades que tiver na zona rural, nas zonas recontidas onde nem materiais didáticos chegam. Apesar deste mar de dificuldades, a educação formal em Moçambique avança e forma acadêmicos. Os alunos do ensino primário enfrentam todo tipo de dificuldade na sua aprendizagem. As infraestruturas são precárias. Para chegar a muitas escolas, principalmente nas zonas rurais, os alunos percorrem muitos quilômetros. Muitas delas não possuem salas e há falta de materiais do tipo: livro, lápis, caderno, entre outros. O estado só garante o livro escolar, mas, muitas vezes, esse livro não chega para todos os alunos.

O plurilinguismo em Moçambique influencia na formação de moçambicanismos, que constituem um léxico identitário do português de Moçambique e estão presentes nas obras literárias, refletindo a realidade sociolinguística moçambicana ao nível lexical, por exemplo. Outrossim, os professores enfrentam dificuldades em compreender o significado de algumas unidades lexicais nos textos literários, porque não existe ainda um dicionário do português de Moçambique. Em 2002, foi publicado um "Minidicionário de Moçambicanismos" escrito por Hildizina Dias e "Moçambicanismos: para um léxico de usos do português moçambicano" da autoria de Lopes, Sitoe e Nhamuende (2002). Estudos e pesquisas estão sendo desenvolvidos em Moçambique e no estrangeiro de forma que num futuro breve se possa publicar uma obra que ilustre exaustivamente o léxico moçambicano.

$\mathrm{Na}$ sala de aula, os moçambicanismos se manifestam de diversas formas tanto na fala quanto na escrita dos alunos embora sendo "bloqueados", ou melhor, corrigidos pelos métodos da escola moçambicana através do conceito de "erro" que 
pune, que sanciona e faz com que os alunos repitam de classe (ou série) várias vezes. A escola finge ter professores especializados no português europeu e, ao fim do ano, colhe fracos resultados e baixa qualidade por causa dessa falsa crença de que a melhor variedade do português é a europeia. Essa atitude incentiva a intolerância linguística no contexto moçambicano. Em muitas partes da zona rural, o aluno só fala em português na sala, com o professor e colegas. Fora da sala e junto à família, a língua predominante é uma língua do grupo bantu.

\section{Referências}

Benveniste, Emile. Problemas de linguística geral I. Trad. Maria da Glória Novak e Maria Luisa Neri. 5.ed. Campinas, SP: Pontes, 2005.

Brasil. Resolução CEB n ${ }^{\circ}$ 3, de 10 de novembro de 1999. Fixa Diretrizes Nacionais para o funcionamento das escolas indígenas e dá outras providências. 1999a. Disponível em: http://portal. mec.gov.br/secad/arquivos/pdf/educacaoindigena.pdf. Acesso em: 11 de abr.2017.

Brasil. Parecer n ${ }^{\circ}$ 14/99, de 14.9.99, do Conselho Nacional de Educação. Diretrizes Curriculares Nacionais da Educação Escolar Indígena. 199b. Disponível em: http://portal.mec.gov.br/secad/ arquivos/pdf/educacaoindigena.pdf. Acesso em 11 de abr.2017.

Borba, Francisco da Silva. Introdução aos estudos linguísticos. São Paulo: Nacional, 1967.

Calvet, Louis-Jean. Trois espaces linguistiques face aux défis de la mondialisation. 1 ère table ronde Identité et multiculturalisme. Paris, 20 - 21 mars 2001. Disponível em: <http://ftp.infoeuropa. eurocid.pt/database/000043001-000044000/000043048.pdf>. Acesso em: 30 mar.2017.

Calvet, Louis-Jean. As políticas linguísticas. Trad. Isabel de O. Duarte, Jonas Tenfen e Marcos Bagno. São Paulo: Parábola/IPOL, 2007.

Calvet, Louis-Jean.Nouvelles perspectives sur les politique linguistiques: le poids des langues. Gragoatá. n³2, nº 1, p.55-73. Niterói, 2012.

Chicumba, Mateus. A educação bilíngue em Angola e o lugar das línguas nacionais. p.241254. Disponível em: $<$ http://pascal.iseg.utl.pt/ cesa/images/files/inprogress2_texto16.pdf $>$. Acesso em: 30 mar.2017.

Costa, Marcos Antônio. Estruturalismo. In: Martelotta, Mário Eduardo (Org.). Manual de linguística. São Paulo: Contexto, 2009, p.114-126.

Dias, Hildizina. Minidicionário de Moçambicanismos. Maputo: Imprensa universitária, 2002.

Gonçalves, Rita; Hagemeijer, Tjerk. O português num contexto multilíngue: o caso de São Tomé e Príncipe. Revista Cientifica da UEM. Maputo. v.1, n.1, p.87-107, 2015.

INE. Instituto Nacional de Estatística. Recenseamento geral da população e habitação. Maputo: INE, 2007

Ki-Zerbo, Joseph. Para quando a África: entrevista com René Holenstein. Trad. de Carlos A. de Brito. Rio de Janeiro: Pallas, 2006.

Lopes, Armando Jorge; Sitoe, Salvador Júlio; Nhamuende, Paulino José. Moçambicanismos: para um léxico de usos do português moçambicano. Maputo: Livraria Universitária, UEM, 2002 
Lyons, John. Linguagem e linguística: uma introdução. Trad. Marilda W. Averbug e Clarisse S. de Souza. Rio de Janeiro: Guanabara, 1987.

Moçambique. Constituição da República de Moçambique. Maputo: Imprensa Nacional, 2004.

Malmberg, Bertil. As novas tendências da linguística: uma orientação à linguística moderna. Trad. Francisco da Silva Borba. São Paulo: Companhia Editora Nacional/Ed.USP, 1971.

Namone, Dabana; Timbane, Alexandre António. Consequências do ensino da língua portuguesa no ensino fundamental na Guiné-Bissau 43 anos após a independência. Mandinga. Redenção, v.1, n.1, p. 39-57, jan./jun. 2017.

Ndombele, Eduardo David. Gestão de multilinguismo em Angola: reflexão sobre o ensino de línguas angolanas de origem bantu na província do Uíge. Verbum. v.6, n.1, p.33-44, jan.2017.

Neville, Alexander. Language policy and national unity in South Africa/Azania. Cape Town: Buchu Books, 2013. Disponível em: < https://www.marxists.org/archive/alexander/language-policy-and-national-unity.pdf $>$. Acesso em: 12 mar.2017.

Ngunga, Arlindo. Introdução à linguística bantu. 2.ed. Maputo: Imprensa Universitária, 2014.

Ngunga, Arlindo et al. Educação bilíngue na província de Gaza: avaliação de um modelo de ensino. Maputo: CEA, 2010.

Ngunga, Arlindo; Bavo, Názia N. Práticas linguísticas em Moçambique: avaliação da vitalidade linguística em seis distritos. Maputo: CEA/UNESCO, 2011.

Ngunga, Arlindo; Faquir, Osvaldo G. Padronização da ortografia de línguas moçambicanas: Relatório do III Seminário. Col. As nossas línguas. Maputo: CEA, 2011.

Nhampoca, Ezra. Ensino bilíngue em Moçambique: introdução e percursos. Working Papers, v.16, n², p.82-100, Florianópolis, ago./dez. 2015. Disponível em: <https://periodicos.ufsc.br/index.php/workingpapers/article/view/1984-8420.2015v16n2p82/33217>. Acesso em 26 mar.2017

Ntondo, Zavoni. Morfologia e sintaxe do Ngangela. Col.Universitária: Série Linguística. Luanda: Editorial Nzila, 2006.

Ponso, Letícia Cao. As línguas não ocupam espaço dentro de nós: práticas, atitudes e identidades linguísticas entre jovens moçambicanos plurilíngues. 2014, 315f. Instituto de Letras, Universidade Federal Fluminense, Niterói, 2014.

Rodrigues, Ângela Lamas. Dominação e resistência na África: a questão linguística. Gragoatá. Niterói, n, 19, p. 161-176, 2 $\mathrm{sem} .2005$.

Rodrigues, Ângela Lamas. A lingua inglesa na África: opressão, negociação, resistência. Campinas-SP: Ed. Unicamp, 2011.

Rodrigues, Ayron. Tupi, tupinambá, línguas gerais e português do Brasil. in: Noll, Volker; Dietrich, Wolf. (Org.). O português e o tupi no Brasil. São Paulo: Contexto, 2010. p. 27-47.

Saussure, Ferdinand. Curso de linguística geral. Trad. Antônio Chilini, José Paulo Paes, Izidoro Blikstein. São Paulo: Cultrix, 2006.

Severo Cristine Gorski. Política (s) linguística(s) e questões de poder. Alfa, São Paulo, nº 57, v. 2. p. 451-473, 2013. Disponível em: <http://seer.fclar.unesp.br/alfa/article/viewFile/5132/4670>. 
Acesso em: 18 mar. 2017.

Tarallo, Fernando; Alkmin, Tânia. Falares crioulos: línguas em contato. São Paulo: Ática, 1987.

Timbane, Alexandre António; Quebi, Duarte Olossato; Abdula, Rajabo Alfredo Mugabo. As políticas linguísticas e o desenvolvimento endógeno em África. Web-Revista Sociodialeto. Campo Grande, v.5, nº13, p.178-202, 2014. Disponível em: <http://www.sociodialeto.com.br/edicoes/18/08082014101950.pdf>. Acesso em: 17 mar. 2017.

Timbane, Alexandre António; Nhampoca, Ezra Alberto Chambal. A produção, promoção e divulgação em línguas bantu moçambicanas: Bulu na mufundhisi Bento Sitoe. Linguagem: estudos e pesquisas. Catalão. v.20, n.2, p.17-30, 2016. Disponível em: <https://www.revistas.ufg.br/lep/ article/view/45812/22560>. Acesso em: 17 mar. 2017.

UNESCO. Declaração Universal dos Direitos Linguísticos. Barcelona. 6- 9 de Junho de 1996. Disponível em: < http://www.dhnet.org.br/direitos/deconu/a_pdf/dec_universal_direitos_linguisticos.pdf $>$. Acesso em: Acesso em: 19 mar. 2017. 